\title{
Apuntes sobre Vidas en verso: autoficciones poéticas, de Laura Scarano santa Fe: Ediciones
}

UNL, 2014 .

• Gabriela Sierra / Universidad Nacional del Litoral - CONICET / gabisierra@hotmail.com.ar

Vidas en verso: autoficciones poéticas es el resultado del trabajo que Laura Scarano desarrolla como investigadora Principal del conicet, además de que se enmarca en otros proyectos grupales tanto en su trabajo como docente en la Universidad Nacional de Mar del Plata, así como en su labor de investigadora externa en España.

El texto se organiza en tres partes: un estudio teórico, una antología y un conjunto de propuestas de lecturas de los poemas incluidos en la misma.

En dicho estudio teórico, la autora se ocupa principalmente de analizar una poética del nombre de autor, el problema de la autoría y la figuración del escritor en la obra, pasando obligadamente por la revisión de discusiones en torno al género autobiográfico. Pero la apuesta más fuerte, es el desarrollo de estos problemas teóricos en el género lírico, en el cual no se los suele indagar.

En su análisis de la autoría, si bien Scarano no elude los aportes de teóricos como Bajtín, Derrida, De Man, Barthes, Foucault, Lejeune, Ricoeur, Bourdieu, Taylor, entre otros - se centra en la revisión de dos posturas antagónicas: por un lado, en los movimientos deconstructivos del sujeto autoral y por otro lado, en la reposición del nombre de autor desde líneas pragmáticas que lo conciben como categoría social. Y es en esta última línea donde sus ideas se asientan y desarrollan.

La rigurosidad del estudio lleva a Scarano a debatir sobre las transformaciones del sujeto poético, es decir, explora las demarcaciones que se producen entre lo biográfico y lo ficticio a partir de las voces del poema. Como ella misma enuncia dialogando con un texto de Dominique Combe:

el comportamiento del lector al «leer» el "yo lírico» como «metonimia» del autor, no abandona la certeza de que estamos frente a «un sujeto doble», que no se agota en las referencias autobiográficas y asume otra estatura —analógica o alegórica. (...) Esta noción de «desvío figurado» es una forma de resolver la cesura aporética de los términos «sujeto empírico» y «sujeto retórico», y habilita lo que llamamos «doble agencialidad» del sujeto poético, que produce en los lectores un incesante vaivén. (24-25)

Para atender dichas cuestiones, Scarano retoma no sólo las especulaciones de Dominique Combe sino también la de autores como Käte Hamburger, Kinereth Meyer, Ángel Luján Atienza, Paul Ricoeur, Karlheinz Stierle, Jorge Monteleone, entre otros. Y en esa senda, no deja de explorar y de transparentar la categoría filosófica de identidad en la que se circunscriben sus estudios. 
En esta perspectiva, la autora también se ocupa, a partir de la metaficción, de pensar estos problemas sobre lo biográfico y lo ficticio en el poema. Desde este procedimiento que ha sido estudiado principalmente en el género narrativo, Scarano desprende su reflexión invitándonos a pensar en un metapoema autoral, tipología que piensa como «la especie que exhibe al autor en el texto, alterando y transponiendo las fronteras tradicionales entre ambos universos; $y$ funde en la homonimia el horizonte biográfico del poeta con su realización textual» (44).

Desde aquí, trazando un recorrido que da cuenta de las incesantes redes que existen entre los universos intra y extratextuales, se desprende la reflexión sobre la categoría de autoficción, momento en el que Scarano analiza sus diversas significaciones, sus alcances y sus límites. Asimismo, dialoga y polemiza con las propuestas sobre la misma categoría de algunos autores como Regine Robin, Vincent Colonna, José María Pozuelo Ivancos, Manuel Alberca, Alicia Molero de la Iglesia, Phillipe Lejeune.

Hacia el final del estudio, Scarano defiende el carácter relacional de la referencialidad y la ficción, proyectando un interrogante central que no se pierde de vista en el recorrido teórico y que se relaciona con poder pensar qué efectos de lectura se desencadenan cuando se textualiza su autor. Para responder al mismo, la autora tiene en cuenta que sus usos difieren de acuerdo con las poéticas en las que este procedimiento se inscribe, pero en general, sostiene que esta inscripción del autor en la obra despliega un doble pacto, el poema siempre se teje en la tensión entre lo autobiográfico y lo ficcional.

En la lectura del segundo apartado hallamos una antología de poemas con nombre de autor de espańoles y latinoamericanos que han publicado en el siglo xx y xxi. Se trata de un corpus amplio y valioso por la variedad de autores de diferentes latitudes y tradiciones poéticas muy disímiles, con la inclusión de algunos poemas clásicos y otros menos conocidos. Y tanto el dossier de poemas como sus lecturas se configuran a partir de diversos intercambios que la autora tuvo con estudiantes que cursaron un seminario que dictó en el año 2012 en la Universidad Nacional de Mar del Plata. De este modo, en la tercera parte se recuperan voces y posturas de sus alumnos de posgrado. En este sentido, las lecturas críticas que se encuentran en la antología dan respuestas a los distintos usos de la inscripción del nombre de autor en los poemas, generando diálogos entre ellos al revisar qué juegos y compromisos con el mundo habilita dicha inscripción. Si bien todos los trabajos tienen en cuenta que sus usos son diversos de acuerdo a las poéticas de cada autor, en ellos encontramos el énfasis en generar un eco con el estudio teórico de Laura Scarano.

Para concluir, destacamos que dicho trabajo no formula resultados cerrados, por el contrario abre un continuum de nuevos problemas e interrogantes. Esto permite revisitarlos desde el intercambio y la discusión. Ya que como dice Scarano: «sabemos que la poesía pone en escena una multiplicidad de subjetividades, y nadie creerá ingenuamente en la identidad ontológica de esos antropónimos. Pero vale la pena detenerse en sus alcances, implicancias y efectos» (80). 